\title{
Aplikasi WiMAX
}

\author{
Oleh: \\ Yenniwarti Rafsyam, Milda Yuliza, Lifwarda
}

Staf Pengajar Teknik Elektro Politeknik Negeri Padang

\begin{abstract}
WiMAX is Broadband Wireless Acces (BWA) technology evolution with interactive fitur. WiMAX not only have issue about data speed problem but also about open standard. It means, communications between WiMax instruments between some different vendors are not proprietary. WimAX orientations are not only for fixed market, but also for portable and mobile market. WiMAX with high speed data (up to $70 \mathrm{MBps}$ ) is suitable to apply in last mile broadband connections, backhaul and high speed enterprise.
\end{abstract}

Keyword: WiMax, vendor, broadcast

\section{PENDAHULUAN}

WiMAX menurut James A. Johnson (Vice President, Intel Communications Group/General Manager, Wireless Networking Group), istilah WiMAX berasal dari singkatan wireless (disingkat Wi) Microwave Access (disingkat MAX). WiMAX menyerupai Wi-Fi dalam hal penggunaan teknologi modulasi yang sama.

Teknologi

WiMAX memungkinkan untuk memancarkan berbagai sinyal dalam jarak yang sangat berdekatan, tanpa harus cemas bahwa aneka sinyal tersebut akan saling mengganggu/berinterferensi. Dengan demikian, kita bisa menumpangkan lalu lintas data dengan kepadatan tinggi dalam berbagai kanal tersebut. Dengan banyaknya kanal yang bisa ditumpangi oleh data yang berlimpah dalam satu waktu, ISP atau penyedia layanan broadband bisa menghadirkan layanan berbasis kabel atau DSL untuk banyak pelanggan sebagai ganti media kabel tembaga.

Dibandingkan dengan teknologi wireless lainnya, Worldwide Interoperability for Microwave Access (WiMAX) merupakan salah satu teknologi yang baru. Bahkan pengujian perangkat dari beberapa vendor untuk mendapat sertifikat "WiMAX" baru dimulai sekitar bulan Juli 2005. Untuk standar WiMAX mobile (IEEE 802.16e) baru disahkan sekitar pertengahan tahun 2006. Posisi WiMAX dikaitkan dengan teknologi wireless lain dapat digambarkan sebagai berikut: 


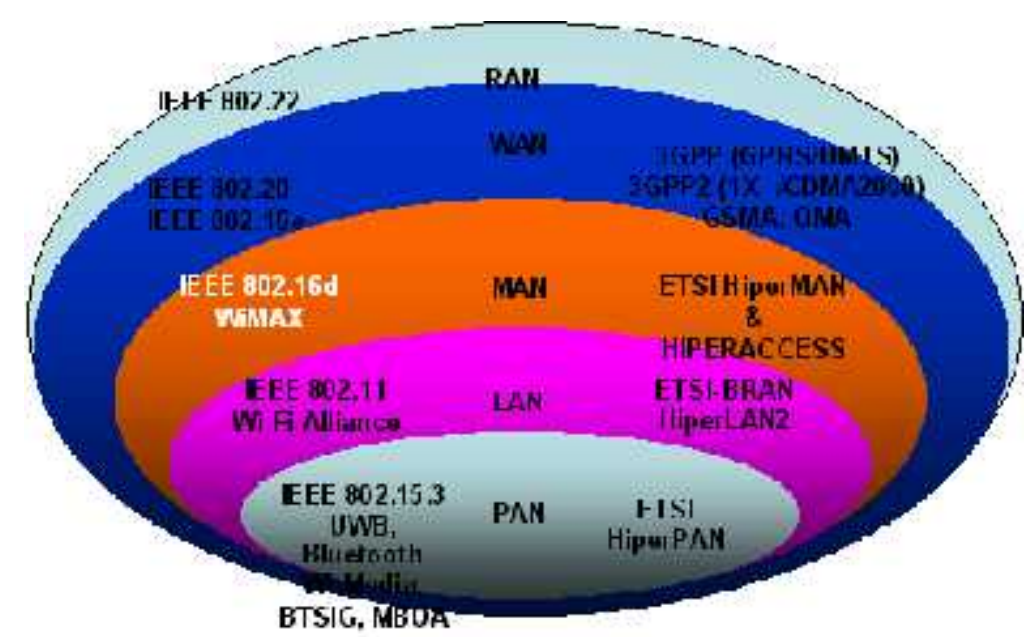

Gambar 1. Posisi Teknologi WiMAX

WiMAXmerupakan penggabungan antara standar IEEE802.16 dengan ETSI HiperMAN. Standar keluaran IEEE banyak digunakan secara luas di daerah asalnya, yaitu Eropa dan sekitarnya. Untuk dapat membuat teknologi ini digunakan secara global, maka diciptakan WiMax Teknologi WirelessMANTM / IEEE 802.16 / WiMax dapat meng-cover area sekitar 50 Kilometer, dimana ratusan pelanggan akan di-share sinyal dan kanal untuk mentransmisikan data dengan kecepatan sampai 155 Mbps. Standar ini juga mengatur penggunaan perangkat nirkabel untuk keperluan jaringan perkotaan (Metropolitan Area Network/MAN). Standar ini khususnya dirancang untuk memenuhi kebutuhan jaringan akan akses nirkabel berkecepatan tinggi atau BWA (broadband wireless access).

Standar $802.16 \quad$ (dan turunanannya) beroperasi pada pita frekuensi radio antara $2 \mathrm{GHz}$ sampai $11 \mathrm{GHz}$. Standar ini memiliki transfer rate $75 \mathrm{Mbit}$ per detik dengan tingkat latency yang rendah, dan efisiensi penggunaan ruang spektrum frekuensi.

Aspek keamanan merupakan aspek yang sangat penting dan akan dievaluasi oleh para pengguna internet dengan menggunakan fasilitas ADSL atau teknologi kabel modem maupun yang berlangganan dengan teknologi WiMax.

Sistem pengamanan data dilakukan pada layer physical (PHY) dan data link layer (MAC) pada suatu arsitektur jaringan, tepatnya pada base station (BS) untuk didistribusikan ke wilayah sekelilingnya dan subcriber station (SS) untuk komunikasi point to multipoint. Base Station (BS) dihubungkan secara langsung dengan jaringan umum (public network), Secara umum Wireless MANTM traffic dibedakan menjadi tiga bagian, yaitu:

1. Pelanggan mengirimkan data dengan kecepatan 2-15 Mbps dari subcriber station (SS) ke base station (BS).

2. Base station akan menerima sinyal dari berbagai pelanggan dan mengirimkan pesan melalui wireless atau kabel ke switching center melalui protokol IEEE 802.16.

3. Swicthing center akan mengirimkan pesan ke internet service provider (ISP) atau publicswitched telephone network (PSTN).

Ketiga bagian tersebut di atas secara blok dapat di lihat pada Gambar 2 di bawah ini: 
ISSN: 2085-6989

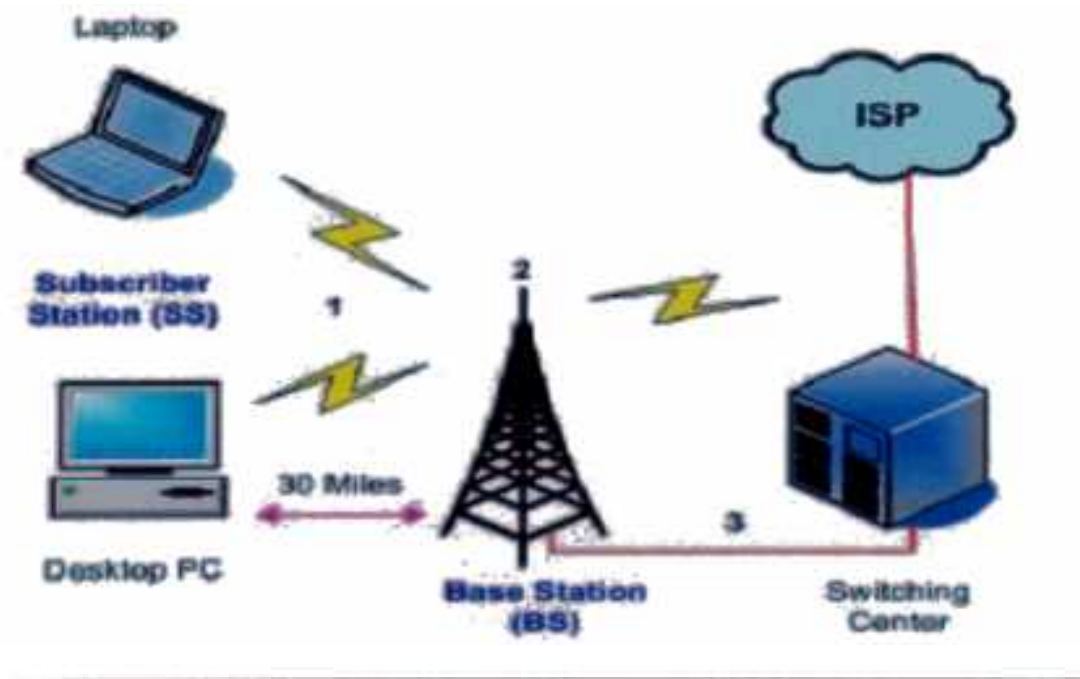

Gambar 2. Trafik yang terjadi pada WiMAX

Pada Gambar 2 Laptop dan desktop personal computer (PC) berfungsi sebagai subscriber station (SS), tower antena beserta perangkatnya sebagai base station (BS) dan swicthing center sebagai pengaturpilihan koneksi ke internet service provider (ISP).

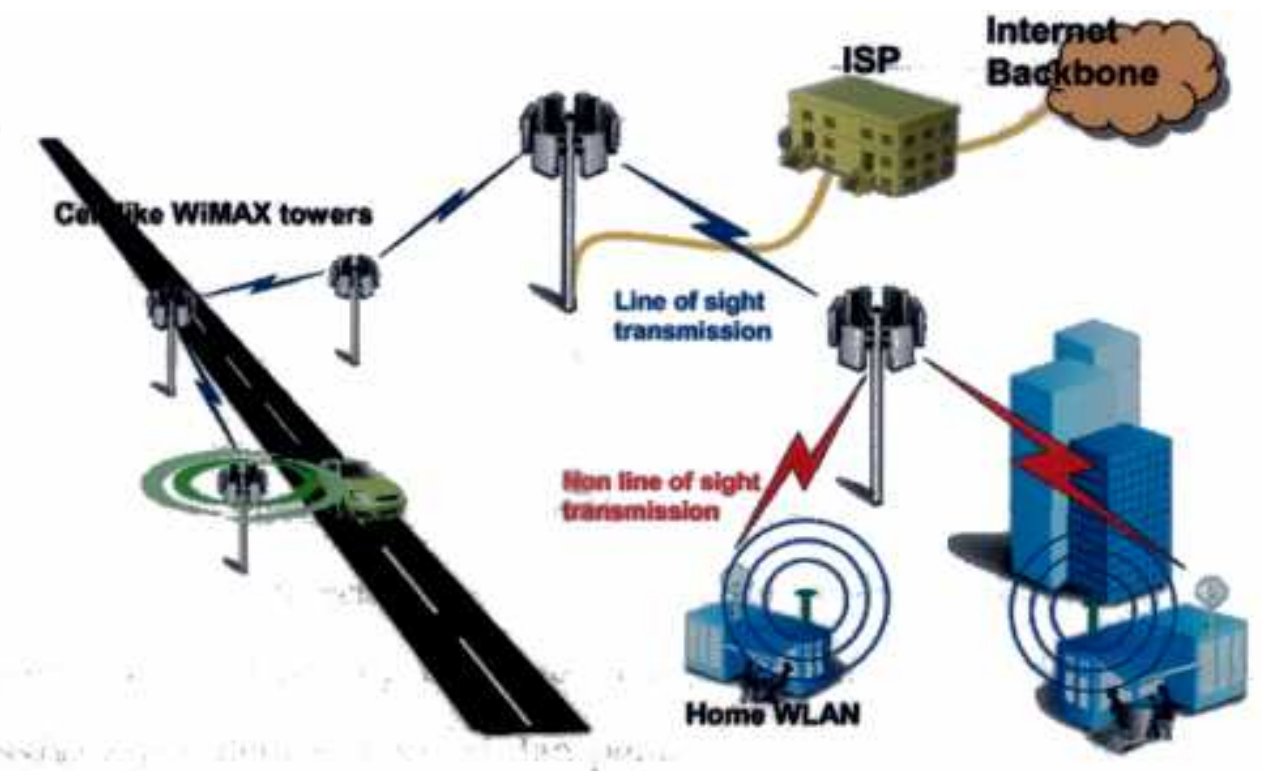

Sumber : Intelligent Wireless Network Group (IWING)CPE Depertement, Kasetsart University

Gambar 3. Arsitektur WiMAX. 
Pada awalnya standar IEEE 802.16 beroperasi pada frekuensi 10-16 Ghz dan memerlukan tower line of sight, tetapi penggembangan IEEE 802.16a yang disahkan pada bulan Maret 2004, menggunakan frekuensi yang lebih rendah yaitu sebesar 2-11 Ghz, sehingga mudah di atur, dan tidak memerlukan line-of-sight. Cakupan area yang dapat dicoverage sekitar $50 \mathrm{Km}$ dan kecepatan transfer data sebesar $70 \mathrm{Mbps}$. Pengguna tidak akan kesulitan dalam mengulur berbagai macam kabel, apalagiWiMAX mampu menangani sampai ribuan pengguna sekaligus.

Varian-varianWiMAX dimaksudkan untuk mengembangkan performance dan kemampuan dari teknologi yang digunakannya, agar menjadi lebih hebat dan dapat meluas penggunaannya. Untuk mengembangkan jangkauan dan daya jualnya, maka standar IEEE 802.16 direvisi menjadi IEEE 802.16a. Standar teknis IEEE $802.16 a$ inilah yang banyak digunakan oleh perangkat-perangkat dengan sertifikasi WiMAX.
Selain IEEE 802.16a, varian lainnya adalah IEEE $802.16 \mathrm{~b}$ yang banyak menekankan segala keperluan dan permasalahan dengan Quality of service (QoS), IEEE 802.16c banyak menekankan pada interoperability dengan protocol-protokol lain, IEEE $802.16 d$ merupakan revisi dari IEEE $802.16 \mathrm{c}$ ditambah dengan kemampuan untuk access point, serta IEEE 802.16d menekankan pada masalah mobilitas. Perkembangan dari WiMAX dapat diilustrasikan pada Gambar 4 dan Gambar 5.

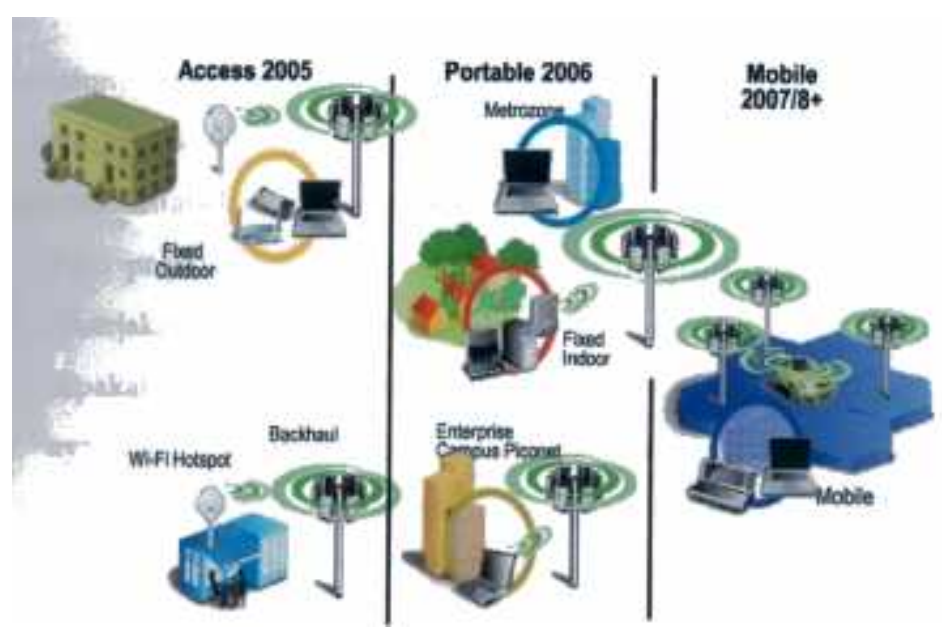

Sumber : Intelligent Wireless Network Group (IWING)CPE Department, Kasetsart University

Gambar 4. Perkembangan WiMAX 


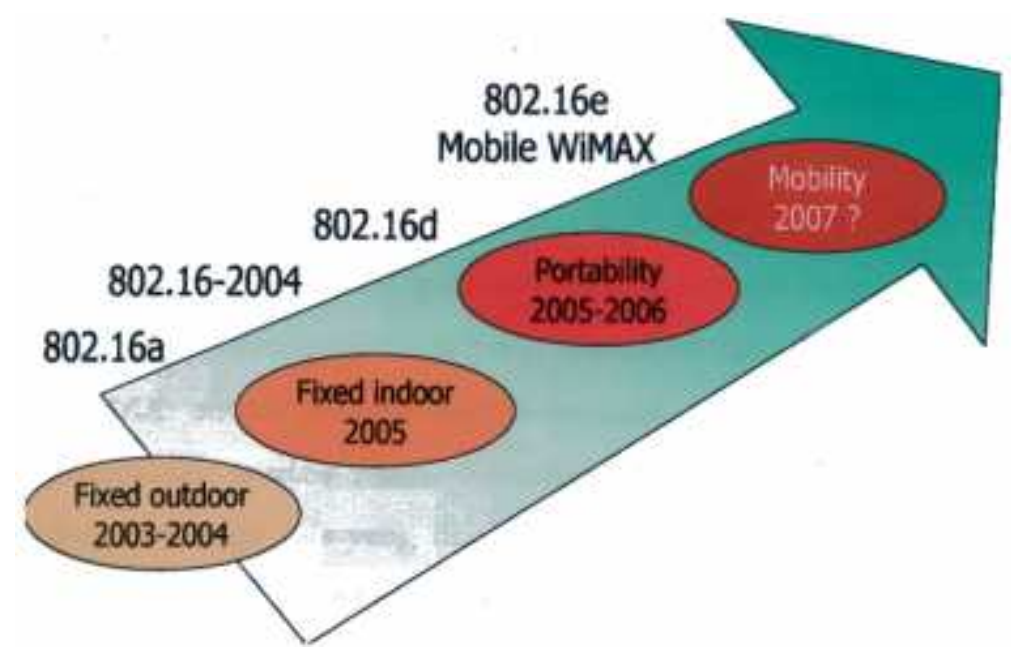

Sumber : Intelligent Wireless Network Group (IWING)CPE Department, Kasetsart University

Gambar 5. Evolusi WiMAX

\section{Aplikasi Backhaul WiMAX}

Untuk aplikasi Backhaul maka WiMAX dapat dimanfaatkan untuk Backhaul WiMAX itu sendiri, Backhaul Hotspot dan Backhaul teknologi lain.
Dalam konteks WiMAX sebagai Backhaul dari WiMAX aplikasinya mirip dengan fungsi BTS sebagai repeater. Tujuannya untuk memperluas jangkauan dari WiMAX, seperti ditunjukkan Gambar 6.

- Backhaul WiMAX

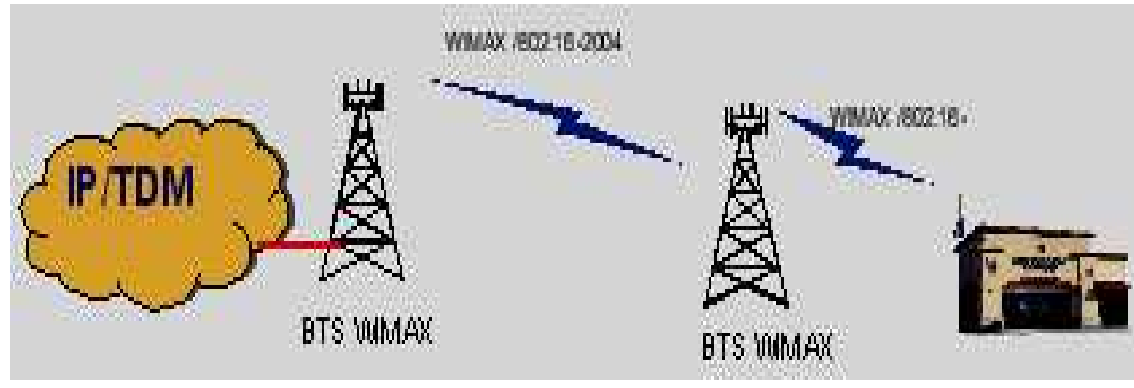

Gambar 6. WiMAX sebagai Backhaul WiMAX

- Backhaul Hotspot

Biasanya hotspot banyak menggunakan saluran ADSL sebagai Backhaulnya. Dengan keterbatasan jaringan kabel, maka WiMAX juga bisa dimanfaatkan sebagai Bakhaulnya Hotspot. Konfigurasinya dapat dilihat seperti pada Gambar 7 berikut: 


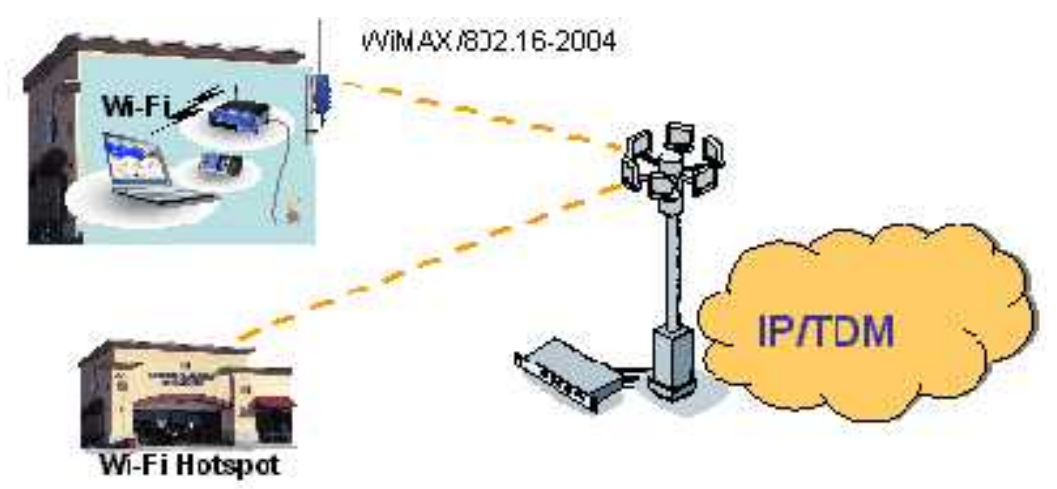

Gambar 7. WiMAX sebagai Backhaul Hotspot

- Backhaul Teknologi Lain

Sebagai backhaul teknologi lain, WiMAX dapat digunakan untuk backhaul seluler. Gambar 8 berikut mengilustrasikan WiMAX untuk menghubungkan MSC/BSC ke BTS seluler

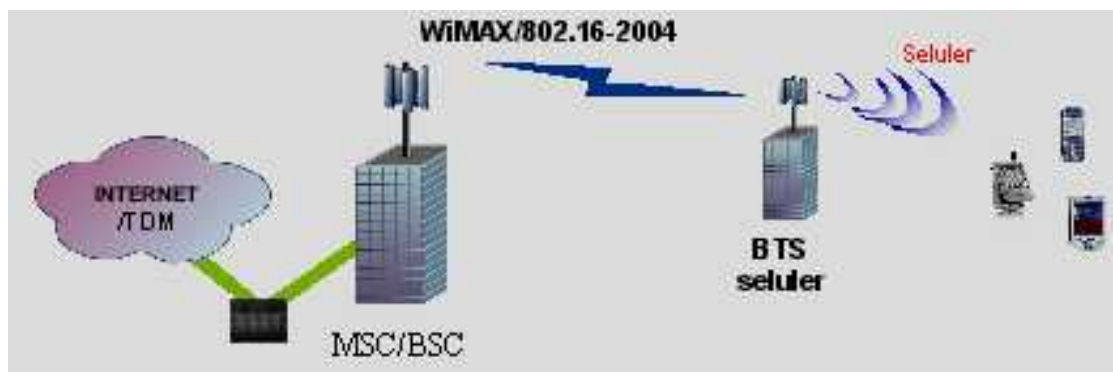

Gambar 8. WiMAX sebagai Backhaul Seluler

\section{Akses Broadband}

Untuk akses broadband WiMAX dapat digunakan sebagai "Last Mile" teknologi untuk melayani kebutuhan broadband bagi pelanggan. Dari pelanggan perumahan maupun bisnis dapat dipenuhi oleh teknologi WiMAX ini, seperti diperlihatkan Gambar 9.

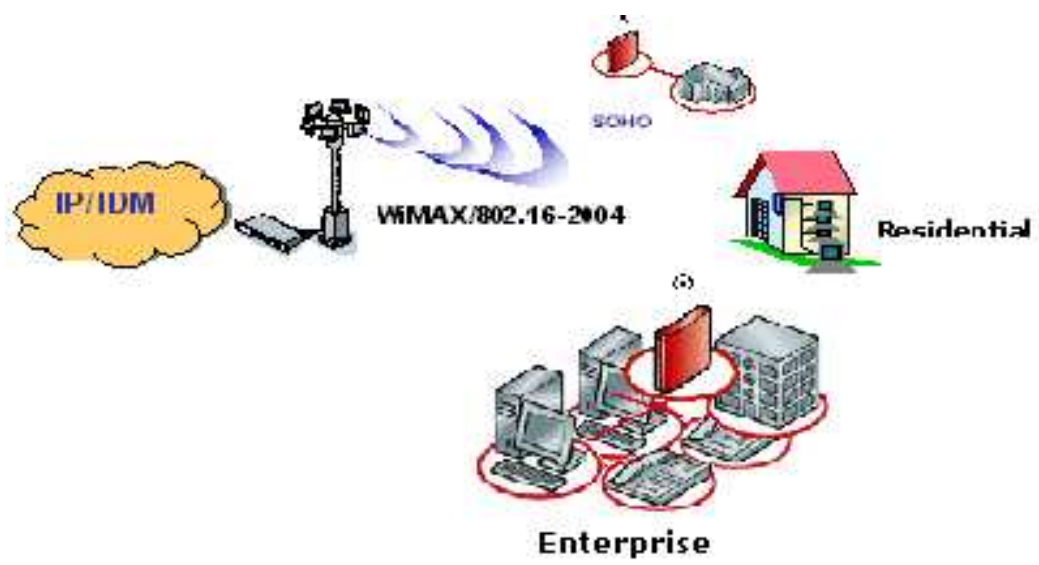

Gambar 9. Aplikasi WiMAX untuk Akses Broadband 


\section{Personal Broadband}

WiMAX sebagai penyedia layanan personal broadband, dapat dibedakan menjadi 2 pangsa pasar yaitu yang bersifat nomadic dan mobile. Gambaran detilnya sebagai berikut:
- Nomadic

Untuk solusi nomadic, maka biasanya tingkat perpindahan dari user WiMAX tidak sering dan kalaupun pindah dalam kecepatan yang rendah. Perangkatnya pun biasanya tidak sesimpel untuk aplikasi mobile. Sususnan perangkat yang digunakan untuk Nomadic seperti ditunjukkan Gambar 10.

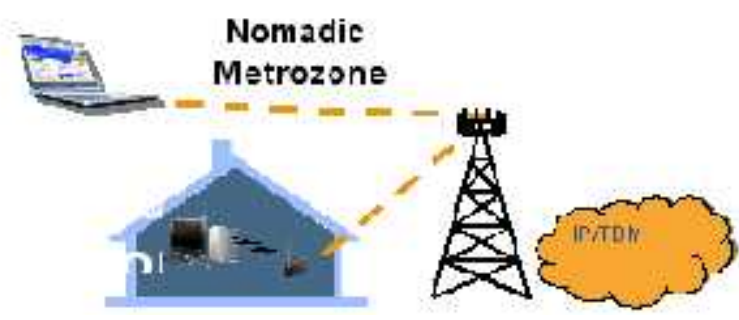

Gambar 10. WiMAX untuk Aplikasi Personal Broadband (Nomadic)

- Mobile

Untuk aplikasi mobile, maka user WiMAX layaknya menggunakan terminal WiFi seperti notebook, PDA atau smartphone. Perpindahan/tingkat mobilitasnya sama dengan WiFi.
Bedanya kalau menggunakan WiMAX maka digunakan WiMAX card yang dipasang di terminal. Gambar 11. berikut mengilustrasikan WiMAX untuk aplikasi mobile.

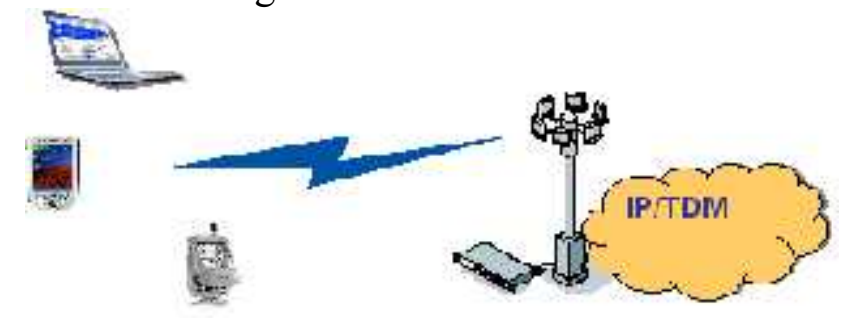

Gambar 11. WiMAX untuk Aplikasi Personal Broadband (Mobile)

\section{KESIMPULAN}

Dengan uraian di atas, maka dapat disimpulkan bahwa WiMAX dapat diimplementasikan untuk:

1. Teknologi Wireless akhir-akhir ini telah berkembang sangat pesat yang menyediakan hubungan komunikasi tanpa tergantung dari jaringan kabel menggunakan telepon atau TV kabel. Dengan adanya teknologi WirelessMANTM maka akan menberikan kemurahan dan kecepatan transfer data dengan akses internet jalur lebar (broadband).

2. Standar IEEE 802.16 memberikan kemudahan dalam akses internet untuk area metropolitan dengan menerapkan 
beberapa base station (BS) yang dapat meng-coverage jutaan subscriber station (SS).

3. Teknologi WiMAX merupakan salah satu solusi untuk dapat mengembangkan teknologi informasidalam suatu kota atau pedesaan karena jangkauannnya sampai jarak $50 \mathrm{Km}$, sehingga memungkinkan untuk mengcoverage seluruhnya.

4. Backhaul, yaitu sebagai backhaul hotspot, WiMAX sendiri maupun teknologi lainnya.

5. Akses Broadband, yaitu untuk memenuhi kebutuhan akses broadband baik untuk enterprise maupun perumahan.

6. Personal broadband, yaitu untuk memenuhi kebutuhan baik untuk nomadic maupun mobile broadband

\section{DAFTAR PUSTAKA}

Gunadi Dwi Hantoro,2005. Sekilas

Tentang WiMAX

Hayri, 2004, WiMAX Koneksi Broadband Lewat Wireless, Majalah PC Media Edisi Juli.

Phonphoem, A, 2007. WiFi-WiMAX Update, Computer Engineering Department Kasetsart University, Thailand.

Santoso. G, Teknik Telekomunikasi.

Siyamta, 2004. Sistem Keamanan Pada

Worldwide Interoperability for

Microwave Access (WiMAX),

Anonim, 2004. Broadband Wireless. The

New Era in Communications, Intel.

Anonim, IEEE 802.16* and WiMAX,

Broadband Wireless Access for

Everyone,

http://www.intel.com/ebusiness/p

df/int el/80216 wimax,pdf

Anonim, WiMAX The Critical Wireless

Standard, http://www.eyeforwireless.com/wim

ax report.pdf, http://www.IlmuKomputer.C om,

Diakses 13 April 2007 jam 12.00. 
ISSN: 2085-6989 